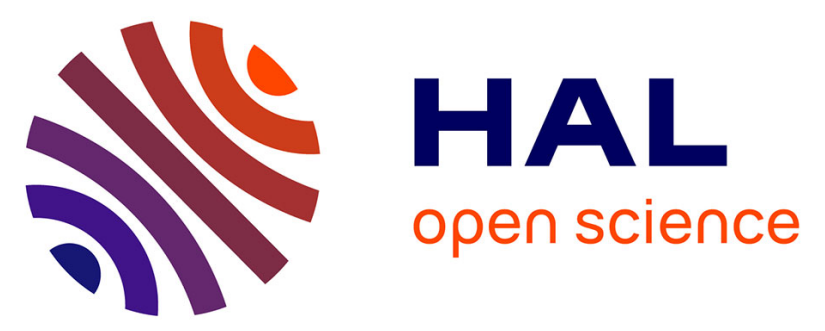

\title{
Auto Tandem Catalysis: Asymmetric Vinylogous Cycloaddition / Kinetic Resolution Sequence for the Enantioselective Synthesis of Spiro-Dihydropyranone from Benzylidene Meldrum's Acid
}

Martial Toffano, Régis Guillot, Chloee Bournaud, Jean-François Brière, Giang Vo-Thanh

\section{To cite this version:}

Martial Toffano, Régis Guillot, Chloee Bournaud, Jean-François Brière, Giang Vo-Thanh. Auto Tandem Catalysis: Asymmetric Vinylogous Cycloaddition / Kinetic Resolution Sequence for the Enantioselective Synthesis of Spiro-Dihydropyranone from Benzylidene Meldrum's Acid. Advanced Synthesis and Catalysis, 2021, 363, pp.4452-4458. 10.1002/adsc.202100559 . hal-03304167

\section{HAL Id: hal-03304167 \\ https://hal.science/hal-03304167}

Submitted on 23 Aug 2021

HAL is a multi-disciplinary open access archive for the deposit and dissemination of scientific research documents, whether they are published or not. The documents may come from teaching and research institutions in France or abroad, or from public or private research centers.
L'archive ouverte pluridisciplinaire HAL, est destinée au dépôt et à la diffusion de documents scientifiques de niveau recherche, publiés ou non, émanant des établissements d'enseignement et de recherche français ou étrangers, des laboratoires publics ou privés. 


\title{
Auto Tandem Catalysis: Asymmetric Vinylogous Cycloaddition / Kinetic Resolution Sequence for the Enantioselective Synthesis of Spiro-Dihydropyranone from Benzylidene Meldrum's Acid.
}

\author{
Martial Toffano*, ${ }^{*}$ Régis Guillot, ${ }^{a}$ Chloée Bournaud, ${ }^{\mathrm{a}}$ Jean-François Brière ${ }^{\mathrm{b}}$ and Giang \\ Vo-Thanh ${ }^{\mathrm{a}}$
}

Dedicated to Prof. Jean-Claude Fiaud on the occasion of his 77th birthday

a Dr. M. Toffano, Dr. C. Bournaud, Dr. R. Guillot and Prof. G. Vo-Thanh

Institut de Chimie Moléculaire et des Matériaux d'Orsay. CNRS UMR 8182, Université Paris Saclay

91405 Orsay Cedex, France.

E-mail: martial.toffano@universite-paris-saclay.fr

b Dr. J.-F. Brière

Normandie Univ, UNIROUEN, INSA Rouen, CNRS, COBRA, 76000 Rouen, France.

\begin{abstract}
A catalytic enantioselective vinylogous domino reaction has been achieved from ketone-derived benzylidene Meldrum's acid and $\alpha$-ketolactones to provide spirolactone dihydropyranones with more than $99 \%$ ee. An Auto Tandem Catalysis (ATC) process resulting from dual and complementary role of (DHQ) $)_{2} \mathrm{PHAL}$ organocatalyst resulted in a sequence involving an asymmetric vinylogous formal $(4+2)$ cycloaddition of benzylidene and the subsequent kinetic resolution operating through a 1,3prototropic shift leading to good yields $(>50 \%)$ and the high selectivity.
\end{abstract}

Keywords: Auto Tandem Catalysis; Asymmetric Catalysis; Kinetic Resolution; Organocatalysis; Meldrum's acid; 1,3 prototropic shift

Accessing chiral enantioenriched molecules is still a major challenge in organic chemistry. Producing highly complex structures while preserving energy, resources and time as well as minimizing waste is even more difficult. Over the years, great attention has been given to domino, tandem, one-pot, multi-components and multi-catalyzed reactions in the synthesis of natural products as well as biologically active compounds. ${ }^{[1]}$ Among these, the enantioselective Auto Tandem Catalysis (ATC) offers a powerful tool owing to the same chiral catalyst promotes at least two different chemical transformations in a single pot, while ensuring the asymmetric induction (Figure 1). The main advantages of this strategy consist both in the multiple role of a single catalyst and the challenging compatibility between reagents to achieve an economical domino process. ${ }^{[2,3]}$ However, despite considerable efforts in this area, ${ }^{[4]}$ examples of ATC process with high enantioselectivity are limited. ${ }^{[5]}$ Moreover, an auto-tandem catalysis in the presence of a Brønsted base is highly desirable to expand its practice in organic synthesis. ${ }^{[4 \mathrm{n}]}$

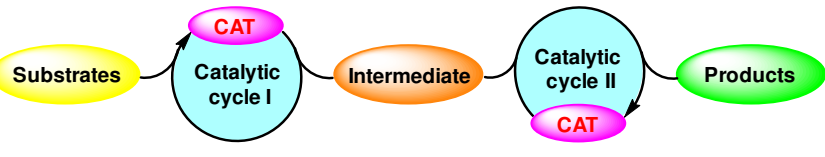

Figure 1. Schematic representation of ATC.

Chiral enantioenriched 5,6-dihydropyran-2-ones is an important heterocyclic structure found in numerous bioactive compounds. Many synthetic strategies have been developed to obtain this motif. ${ }^{[6]}$ Among them, the enantioselective vinylogous reaction is a very important and simple way to construct such a structure bearing a quaternary stereocenter. ${ }^{[7]}$ As such, the development of new reagents to obtain novel chiral 5,6-dihydropyran-2-ones is still of high interest. In the course of our development of efficient enantioselective transformations, we have recently discovered an unprecedented route to 3,6dihydropyran-2-one $\mathbf{3}$ as spiro-[4,5] decane derivatives with up to $98 \%$ ee, from a novel platform in vinylogous series i.e. ketone-derived benzylidene Meldrum's acids 1. $^{[8],[9]}$ The reaction proceeded through a formal $(4+2)$ cycloaddition. ${ }^{[10]}$ Herein, we report a highly enantioselective ATC including a formal $(4+2)$ cycloaddition followed by a kinetic resolution of the intermediate to give access to spiro(bis-lactone) 5,6-dihydropyran-2-ones $\mathbf{4}$ with excellent enantiomeric excesses (Scheme 1). The access to enantioenriched compounds $\mathbf{4}$ from benzylidene Meldrum's acids has never been described so far. 


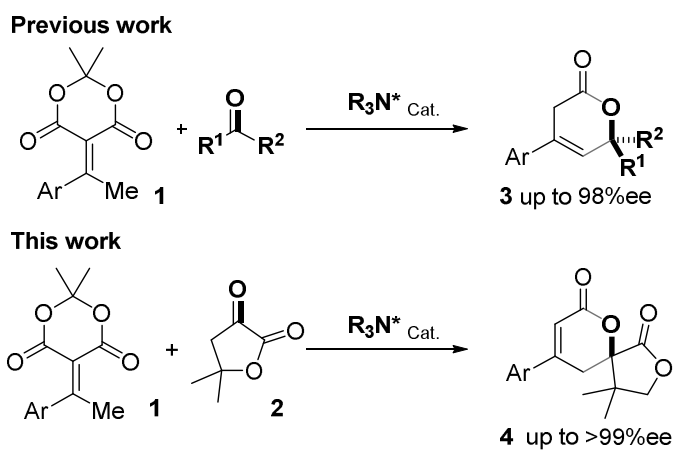

Scheme 1. Benzylidene Meldrum's acid 1 as an original vinylogous platform.

In our previous work, concerning the vinylogous addition reaction of benzylidene $\mathbf{1}$ to ketones, we observed that triethylamine could isomerize the obtained product $\mathbf{3}$ into the conjugated product $\mathbf{4}$ for longer reaction. We therefore envisaged that a basic chiral catalyst could deliver directly the enantioenriched $\alpha, \beta$-unsaturated lactone $\mathbf{4}$, through an economical domino-sequence. Initial investigations examined the base-catalyzed reaction of benzylidene 1a with dihydro-4,4-dimethyl-2,3-furandione $\mathbf{2}$ in the presence of Cinchona-derived catalysts (Scheme 2 and Table 1).
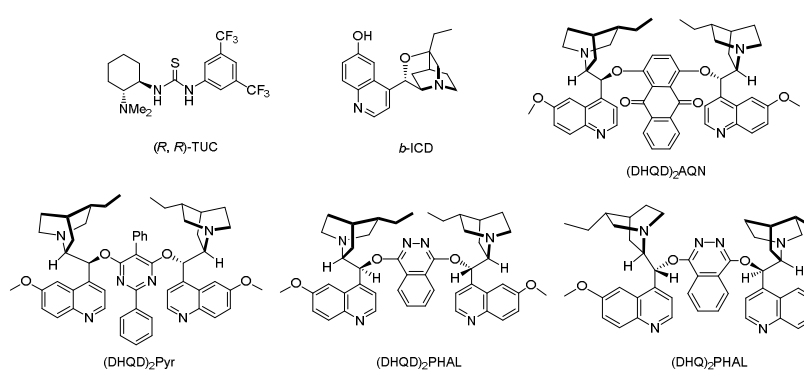

Scheme 2. Catalysts.

Table 1. Asymmetric catalysis with benzylidene 1a and dihydro-4,4-dimethyl-2,3-furandione 2 in the presence of alkaloid catalysts. ${ }^{\text {[a] }}$

\begin{tabular}{|c|c|c|c|c|c|c|}
\hline Entry & Cat & $\begin{array}{c}\text { Conv. } \\
{[\%]}\end{array}$ & $3 a / 4 a$ & $\begin{array}{c}\text { Yields } \\
{[\%]} \\
3 \mathbf{3} / \mathbf{4 a}\end{array}$ & $\begin{array}{c}\mathrm{ee}_{3 a} \\
{[\%]}\end{array}$ & $\begin{array}{c}\mathrm{ee}_{4 a} \\
{[\%]}\end{array}$ \\
\hline 1 & $(R, R)$-TUC & 81 & $99 / 1$ & $76 /$ nd & $92-(R)$ & nd \\
\hline 2 & $\beta-I C D$ & 78 & $96 / 4$ & $76 /$ nd & $35-(R)$ & nd \\
\hline 3 & $(\mathrm{DHQD})_{2} \mathrm{AQN}$ & 91 & $3 / 97$ & $\mathrm{nd} / 71$ & nd & $71-(R)$ \\
\hline 4 & $(\mathrm{DHQD})_{2} \mathrm{Pyr}$ & 94 & $21 / 79$ & $7,5 / 69$ & $86-(S)$ & 89-(R) \\
\hline 5 & $(\mathrm{DHQD})_{2} \mathrm{PHAL}$ & 97 & $25 / 75$ & $20 / 74$ & $89-(S)$ & $92-(R)$ \\
\hline 6 & $(\mathrm{DHQ})_{2} \mathrm{PHAL}$ & 99 & $13 / 87$ & $11 / 86$ & 75- $(R)$ & 98-(S) \\
\hline
\end{tabular}

$\begin{array}{lllllll}7^{[b]} & (\mathrm{DHQ})_{2} \mathrm{PHAL} & 97 & 14 / 86 & 13 / 82 & 12-(S) & 99-(S) \\ 8^{[\mathrm{cc}]} & (\mathrm{DHQ})_{2} \mathrm{PHAL} & 99 & 15 / 85 & 13 / 80 & 66-(R) & 94-(S) \\ 9^{[\mathrm{dc}]} & (\mathrm{DHQ})_{2} \mathrm{PHAL} & 97 & 14 / 86 & 11 / 81 & 51-(R) & 99-(S)\end{array}$

[a] Reaction conditions: 1a $(0.15 \mathrm{mmol}), 2(0.15 \mathrm{mmol})$, catalyst $(20 \mathrm{~mol} \%)$ in DCM $(0.5 \mathrm{M})$ at $25{ }^{\circ} \mathrm{C}$ otherwise noted. Percentage of isolated yields after separation of $\mathbf{3 a}$ and $4 \mathbf{a}$ by column chromatography. The conversion and ratio of isomers $(\mathbf{3 a} / \mathbf{4 a})$ were determined by ${ }^{1} \mathrm{H}$ NMR on the crude product. Enantiomeric excess (ee) was determined by chiral HPLC. The absolute configuration of $\mathbf{3 a}$ and $\mathbf{4 a}$ were determined by X-Ray analysis of pure crystal [b] Performed at $10^{\circ} \mathrm{C}$. [c] Performed at $40^{\circ} \mathrm{C}$. [d] Performed with 10 $\mathrm{mol} \%$ catalyst at $[\mathrm{C}]=1.0 \mathrm{M}$.

Reaction with $\beta$-ICD as catalyst proceeded smoothly to give the non-conjugated product $\mathbf{3 a}$ as the major product with low enantioselectivity (Table 1, entry 2). This result is in agreement with our previous work (entry 1), which showed that many catalysts with an inadequate basicity led to the kinetic product 3a, without subsequent conversion into the conjugated compound 4a $\cdot{ }^{[8]}$ Dimeric alkaloid catalysts afforded 4a as the major product with better selectivity than $\beta$-ICD and in excellent conversion. Thus (DHQD) $2 \mathrm{AQN}$ gave an excellent ratio (3a/4a: $3 / 97)$ with $71 \%$ ee for $\mathbf{4 a}$ (Table 1, entry 3). (DHQD) ${ }_{2} \mathrm{Pyr}$ and (DHQD) $)_{2} \mathrm{PHAL}$ provided the conjugated product $\mathbf{4 a}$ with lower $\mathbf{3 a} / \mathbf{4 a}$ selectivity with (21/79) and (25/75) respectively. Compounds 3a and 4a were isolated in satisfactory yields, but with a significant difference of enantiomeric excesses of $\left(86 \% \mathrm{ee}_{3 \mathrm{a}} / 89 \% \mathrm{ee}_{4 \mathrm{a}}\right)$ and $\left(89 \% e_{3 a} / 92 \% e_{4 a}\right)$ respectively (Table1, entries 4 and 5). This observation was confirmed when using $(\mathrm{DHQ})_{2} \mathrm{PHAL}$ as catalyst. In this case, a 13/87 ratio of 3a/4a with $75 \%$ ee for $(R)-3 \mathbf{a}$ and excellent $98 \%$ ee for $(S)$-4a were obtained (Table 1, entry 6). At lower temperature $\left(10^{\circ} \mathrm{C}\right)$, the conjugated spiro(bis-lactone) (S)-4a was isolated in good yield of $82 \%$ and very high enantiomeric excess of $99 \%$, whereas only $13 \%$ of the non-conjugated compound $(S)$-3a was obtained with a low enantiomeric excess of $12 \%$ (Table1, entry 7). Higher temperature or higher concentration in the presence of lower catalyst loading do not improve the results (Table1, entries 8 and 9). These results are in contradiction with a simple chemical isomerization process of the carbon-carbon double bond of the $\beta, \gamma$ unsaturated lactone 3a to the conjugated lactone 4a. At this stage, we supposed a possible ATC process including an enantioselective formal cycloaddition following by a kinetic resolution (KR) of $\mathbf{3 a}$ to $\mathbf{4 a}$. Surprisingly, this KR would proceed through a 1,3proton shift.

To prove the existence of KR, we first verified that 3a is thermodynamically stable in the reaction conditions without the catalyst. Further investigations were conducted into the isomerization of a racemic mixture of 3a to $4 \mathbf{a}$ in the presence of (DHQ) $)_{2} \mathrm{PHAL}$ at room temperature in order to determine the ratio $\mathbf{3 a} / \mathbf{4 a}$ as well as the enantiomeric excesses of $\mathbf{3 a}$ and 4a and the conversion (Scheme 3 ). ${ }^{[1]}$ To our delight, 
a clear kinetic resolution of racemic 3a was observed with high efficiency in the presence of (DHQ) ${ }_{2} \mathrm{PHAL}$ (Figure 2).
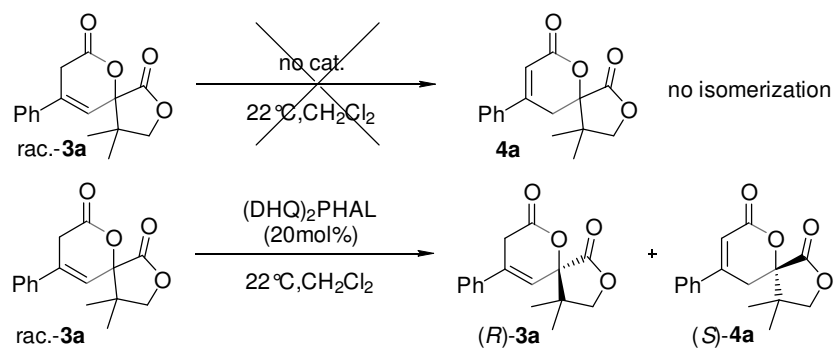

Scheme 3. Thermodynamic stability and kinetic resolution of racemic 3a. ${ }^{[a]}$

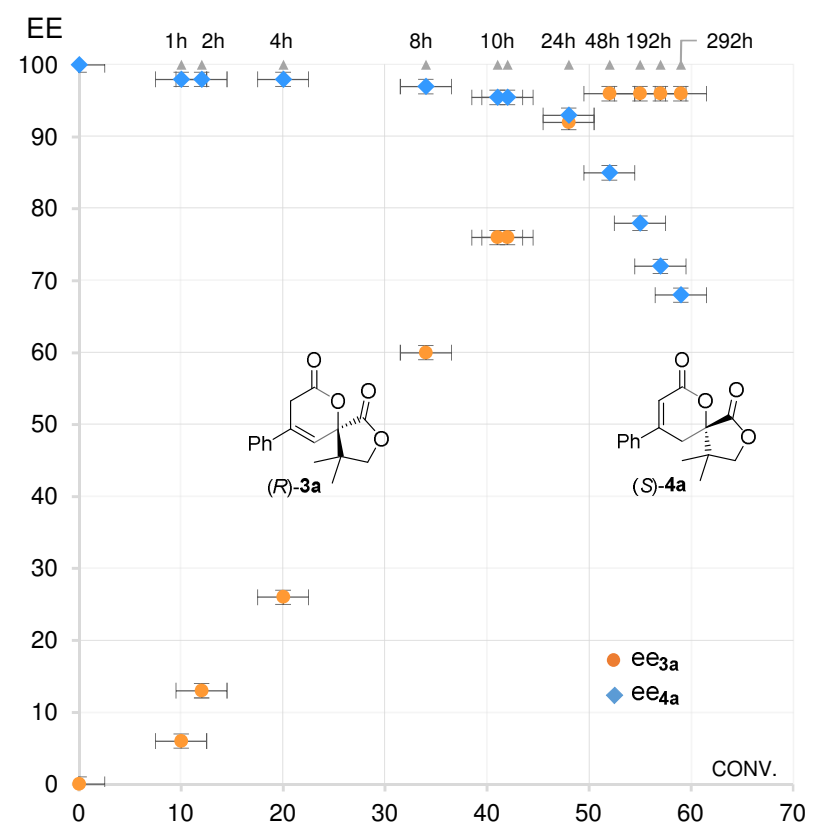

Figure 2. Kinetic resolution of $\mathbf{3 a}$ in the presence of (DHQ) $)_{2}$ PHAL. [a] Enantiomeric excesses were determined by HPLC. Conversion and ratio $\mathbf{3 a / 4 a}$ were determined by ${ }^{1} \mathrm{H}$ NMR (see SI for experimental data).

The enantioenriched conjugated $(S)-\mathbf{4 a}$ was obtained by the preferentially isomerization of $(S)-\mathbf{3 a}$ promoted by the basic (DHQ) $)_{2}$ PHAL catalyst. While the reaction rate was relatively rapid at low conversion, the transformation slowed after 10 hours $(41 \%$ of conversion in 10 hours and $48 \%$ in 24 hours). To achieve conversions of 59\%, 292 hours of reaction time was required. This is proof of the real efficiency of the KR process with an enantioselectivity factor $\mathrm{E}$ $>100 .^{[12]}$ Subsequently, to demonstrate the role of the ATC process during the reaction, a kinetic study was undertaken. Several parameters were investigated such as conversion, $\mathbf{3 a} / \mathbf{4 a}$ ratio and enantiomeric excesses of $3 \mathbf{a}$ and $4 \mathbf{a}$ during the reaction between $1 \mathbf{a}$ and $\mathbf{2}$ catalyzed by (DHQ) 2 PHAL (Table 2).
Table 2. Auto Tandem Catalysis with benzylidene 1a and dihydro-4,4-dimethyl-2,3-furandione 2 in the presence of (DHQ) ${ }_{2}$ PHAL catalyst. ${ }^{[a]}$

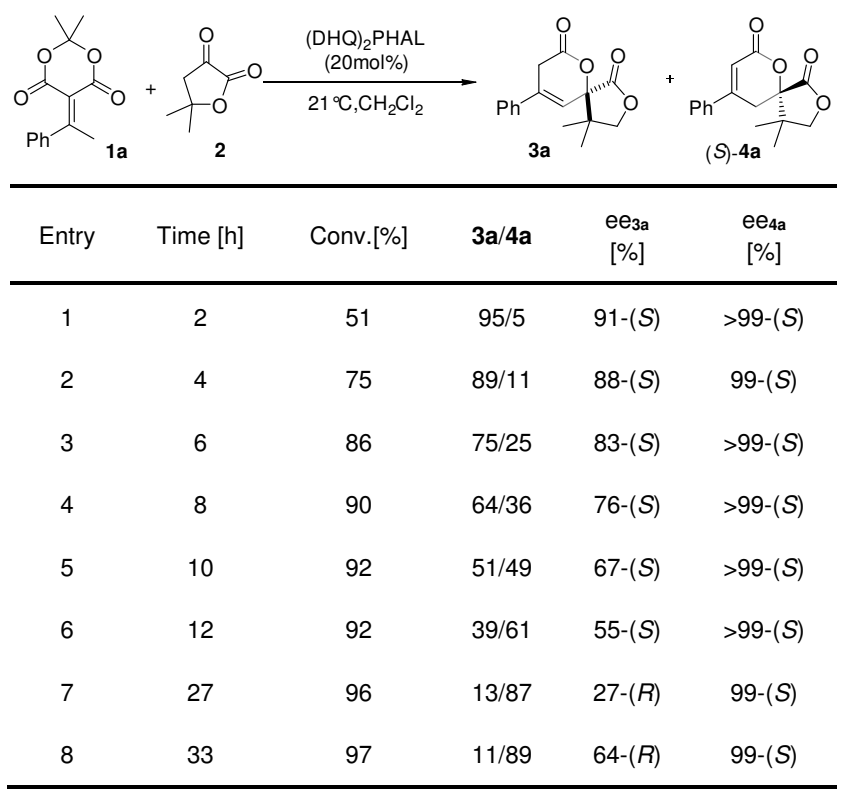

[a] Reaction conditions: 1a $(0.15 \mathrm{mmol}), 2(0.15 \mathrm{mmol})$, catalyst $(20 \mathrm{~mol} \%)$ in $\mathrm{DCM}(0.5 \mathrm{M})$ at $21{ }^{\circ} \mathrm{C}$ Conversion and ratio of isomers $(\mathbf{3 a} / \mathbf{4 a})$ were determined by ${ }^{1} \mathrm{H}$ NMR on the crude product after filtration on a pad of silica gel. Enantiomeric excess (ee) determined by chiral HPLC analysis.

Half conversion was observed after 2 hours (Table 2 , entry 1 ). The ratio of $95 / 5$ confirms the preliminary formation of the non-conjugated compound 3a. The good selectivity of $91 \%$ ee for $(S)-3 \mathbf{a}$, reflects probably the high selectivity when creating the spiro stereogenic center during the first step of the process. At this stage, the enantiomeric excess of $\mathbf{4 a}$ was determined to $(S)$ 99\% ee. During the progress of reaction, we observed a loss of the enantiomeric excess of $(S)$-3a correlating with the variation of $\mathbf{3 a} / \mathbf{4 a}$ ratio (entries 2-5). The equivalent quantity of $\mathbf{3 a}$ and $4 \mathbf{a}$ was obtained around 10 hours of reaction (entry 5). The variation of $\mathbf{3 a} / \mathbf{4 a}$ ratio in favor of $\mathbf{4 a}$ isomer in the course of reaction is related to the decrease of enantiomeric excess of $\mathbf{3 a}$ in reserving the high enantiomeric excess (99\%ee) of $\mathbf{4 a}$, confirming the predominant action of the KR. This proceeded until the change of the major enantiomer of 3a from $(S)$ to $(R)$ between $12 \mathrm{~h}$ and $27 \mathrm{~h}$ reaction time, proving the efficient consumption of $(S)$-3a and resulting in the enrichment of $(R)$ enantiomer (Table 2, entries 6 and 7). This was confirmed by the enantiomeric excess of $(R)$-3a increasing from 27 to $64 \%$ ee for a reaction time from 27 to $33 \mathrm{~h}$ (Table 2, entries 7 and 8). After $27 \mathrm{~h}$ of reaction, $96 \%$ of conversion was obtained with 13/87 ratio in favor of 4a product. $(R)-3 \mathbf{a}$ was detected with $27 \%$ ee whereas $(S)$-4a was isolated with an excellent enantiomeric excess of $99 \%$ ee.

Obtaining the ideal conditions of this ATC reaction through our experiments, our focus turned to the 
substrates scope. A series of benzylidene Meldrum's acid 1a-p were used in the ATC reaction in the presence of dihydro-4,4-dimethyl-2,3-furandione $\mathbf{2}$ leading to the formation of 5,6-dihydropyran-2-ones 4a-p as expected (Table 3). ${ }^{[13]}$

Table 3. Substrates scope for Auto Tandem Catalysis of 5,6dihydropyran-2-ones 4a-p. ${ }^{\text {[a] }}$

\begin{tabular}{|c|c|c|c|c|c|c|}
\hline & $+\int_{-\mathrm{O}-p}^{O}=0$ & $\begin{array}{l}{ }_{2} \mathrm{PHAL} \\
\mathrm{mol} \%) \\
\mathrm{CH}_{2} \mathrm{Cl}_{2}\end{array}$ & $3 a$ & & $(S)-4 a-p$ & \\
\hline Entry & $\operatorname{Ar}$ & $\begin{array}{l}\text { Conv } \\
\text { [\%] }\end{array}$ & $3 / 4$ & $\begin{array}{c}\text { Yields } \\
{ }^{[\%]^{[c]}} \\
\mathbf{3} / \mathbf{4}\end{array}$ & $\begin{array}{c}e_{3 a-p} \\
{[\%]}\end{array}$ & $\begin{array}{c}e_{4 a-p} \\
{[\%]^{[d]}}\end{array}$ \\
\hline $1^{[\mathrm{b}]}$ & 4a: $\mathrm{Ph}$ & 99 & $13 / 87$ & $11 / 86$ & $75(R)$ & $98-(S)$ \\
\hline $2^{[b]}$ & 4b: $4-(\mathrm{CN}) \mathrm{C}_{6} \mathrm{H}_{4}$ & 99 & $14 / 86$ & $11 / 82$ & 75 & $94-(S)$ \\
\hline 3 & 4a: $\mathrm{Ph}$ & 97 & $14 / 86$ & $13 / 82$ & $12(S)$ & $99-(S)$ \\
\hline 4 & 4b: $4-(\mathrm{CN}) \mathrm{C}_{6} \mathrm{H}_{4}$ & 99 & $16 / 84$ & $13 / 64$ & 57 & $>99-(S)$ \\
\hline 5 & 4c: $4-\mathrm{ClC}_{6} \mathrm{H}_{4}$ & 96 & $8 / 92$ & $7 / 87$ & 96 & $>99-(S)$ \\
\hline 6 & 4d: $4-(\mathrm{MeO}) \mathrm{C}_{6} \mathrm{H}_{4}$ & 97 & $20 / 80$ & $11 / 73$ & 37 & $>99-(S)$ \\
\hline 7 & 4e:4-( $\left(\mathrm{NO}_{2}\right) \mathrm{C}_{6} \mathrm{H}_{4}$ & 98 & $25 / 75$ & $8 / 65$ & 33 & $>99$ \\
\hline 8 & 4f: $4-\left(\mathrm{CH}_{3}\right) \mathrm{C}_{6} \mathrm{H}_{4}$ & 98 & $11 / 89$ & $9 / 86$ & 13 & $>99$ \\
\hline 9 & 4g: $4-\left(\mathrm{CF}_{3}\right) \mathrm{C}_{6} \mathrm{H}_{4}$ & 98 & $10 / 90$ & $8 / 72$ & 21 & $>99-(S)$ \\
\hline $10^{[b]}$ & 4h: 2-naphthyl & 99 & $14 / 86$ & $8 / 76$ & 62 & $>99$ \\
\hline 11 & $4 \mathrm{i}: 4-\left(\mathrm{MeO}_{2} \mathrm{C}\right) \mathrm{C}_{6} \mathrm{H}_{4}$ & 93 & $20 / 80$ & $14 / 67$ & 2 & $97-(S)$ \\
\hline 12 & $\begin{array}{l}4 \mathbf{j}: 3,4-\left(-\mathrm{OCH}_{2} \mathrm{O}-\right) \\
\mathrm{C}_{6} \mathrm{H}_{4}\end{array}$ & 98 & $24 / 76$ & $21 / 67$ & 67.5 & $98-(S)$ \\
\hline 13 & 4k: $3-\mathrm{BrC}_{6} \mathrm{H}_{4}$ & 98 & $52 / 48$ & $40 / 44$ & 74 & $>99-(S)$ \\
\hline 14 & 4I: 3- $\left(\mathrm{CH}_{3}\right) \mathrm{C}_{6} \mathrm{H}_{4}$ & 91 & $82 / 18$ & $64 / 15$ & 89 & 99 \\
\hline $15^{[e]}$ & 4I: & 99 & $10 / 90$ & $9 / 87$ & -55 & 98 \\
\hline 16 & 4m: 4-(ibu) $\mathrm{C}_{6} \mathrm{H}_{4}$ & 67 & $95 / 5$ & $58 / \mathrm{nd}$ & 91 & nd \\
\hline $17^{[e]}$ & $4 \mathrm{~m}:$ & 97 & $26 / 74$ & $22 / 65$ & 67 & $>99$ \\
\hline 18 & 4n: 2-furyl & 85 & $99 / 1$ & $62 / n d$ & 83 & nd \\
\hline $19^{[e]}$ & $4 n:$ & 99 & $7 / 93$ & $6 / 82$ & -60 & $97-(S)$ \\
\hline 20 & 4o: $2-\mathrm{ClC}_{6} \mathrm{H}_{4}$ & 61 & $97 / 3$ & $57 /$ nd & 64 & nd \\
\hline $21^{[\mathrm{e}]}$ & 4o: & 93 & $56 / 44$ & $50 / 38$ & 23 & $>99$ \\
\hline 22 & 4p: 1-naphthyl & 81 & $96 / 4$ & $64 / \mathrm{nd}$ & 44 & nd \\
\hline $23^{[\mathrm{e}]}$ & $4 p:$ & 82 & $86 / 14$ & $65 / 9$ & 41 & 96 \\
\hline
\end{tabular}

[a] Reaction conditions: Benzylidene 1 (0.15 mmol), 2 $(0.15 \mathrm{mmol})$, catalyst $(20 \mathrm{~mol} \%)$ in $\operatorname{DCM}(0.5 \mathrm{M})$ at $10{ }^{\circ} \mathrm{C}$ for $24 \mathrm{~h}$ otherwise noted. Conversion and ratio of isomers (3a-p/4a-p) were determined by ${ }^{1} \mathrm{H}$ NMR on the crude product. Enantiomeric excess (ee) determined by chiral HPLC. [b] Reaction performed at $25^{\circ} \mathrm{C}$. [c] Isolated yields after column chromatography. [d] Absolute configuration for $4 \mathbf{a}, 4 \mathbf{b}, \mathbf{4 c}, \mathbf{4 d}, \mathbf{4 g}, 4 \mathbf{i}, \mathbf{4 j}, 4 \mathbf{k}$ and $4 \mathbf{n}$ was determined to be $(S)$ by X-Ray analysis (see ref [14]). [e] 72h reaction time.

As indicated in Table 3, a better enantioselectivity was observed at $10{ }^{\circ} \mathrm{C}$ with benzylidene Meldrum's acids 1a and 1b (entries 1-2 vs 3-4). In all cases, excellent conversions of substrates $\mathbf{4 a - j}$ were obtained in 24hours. In the most of cases, the ratio $\mathbf{3 a - j} / \mathbf{4 a - j}$ in favor of conjugated 4a-j product ranging from $25 / 75$ to $8 / 92$ was detected, leading to satisfactory isolated yields (64 to 87\%). Interestingly, all conjugated products were obtained with very high enantiomeric excess with the majority greater than $99 \%$ ee (entries 3-13). The absolute configuration for compounds $\mathbf{4 a}$, $4 b, 4 c, 4 d, 4 g, 4 i, 4 j, 4 k$ and $4 n$ were determined to be $(S)$ by X-ray analysis. ${ }^{[14]}$ The high enantioselectivity of the process seems to be independent of the electronic nature of the benzylidene, since the presence of electronwithdrawing or donating group do not affect the excellent enantioselectivity of the process. However, the steric effect and more precisely, the ortho or meta position of substituent on the aryl group showed more impact on the ratio $\mathbf{3 / 4}$. For example, substrate $1 \mathbf{k}$ led to an equivalent ratio of $52 / 48$ suggesting probably a slower KR rate compared to other substrates $\mathbf{4 a - j}$. In this case, $\mathbf{3 k}$ was isolated with $74 \%$ ee and more than $99 \%$ ee for $\mathbf{4 k}$ (entry 13 ). The steric effect on the KR rate was confirmed with compounds 11-p. Despite compound 11 bearing a meta-methyl group on the aryl offered a good conversion, compound $\mathbf{4 l}$ was obtained as minor product with only $15 \%$ yield and $99 \%$ ee (entry 14 ). Extending the reaction time to $72 \mathrm{~h}$ led to the inversion of the ratio $\mathbf{3 l} / \mathbf{4 l}$ from $82 / 18$ to $10 / 90$ in favor of the conjugated product $\mathbf{4 I}$ with a limited loss of the enantiomeric excess to $98 \%$ ee (entry 15). Moreover, an inversion of the absolute configuration for the unreactive major enantiomer 3l (-55\% ee) suggests an active KR process. A similar effect was observed for substrates $\mathbf{1 m}$ and $\mathbf{1 n}$ which requires a longer reaction time to give predominantly the desired conjugated products $4 \mathbf{m}-\mathbf{n}$. After $72 \mathrm{~h}$, the ratio value is totally reversed from $99 / 1$ to $7 / 93$ for $3 \mathbf{3 n} / \mathbf{n}$ (entries 18,19 ) and from $95 / 5$ to $26 / 74$ for $\mathbf{3 m} / \mathbf{4 m}$ (entries 16, 17). Conjugated compound $\mathbf{1 m}$ was isolated with excellent enantioselectivity over 99\% ee and 1 n with $97 \%$ ee. The limit of the reaction was observed for substrates 10 and 1p. After $24 \mathrm{~h}$ lower conversions and non-conjugated products 30 and 3p were obtained as major product with $97 / 3$ and 96/4 ratio respectively along with moderate enantiomeric excesses (64 and $44 \%$ ee, entries 20 , 22). Longer reaction time slightly increase the ratio of conjugated product to only 56/44 for 3o/4o and $86 / 14$ for $\mathbf{3 p / 4} \mathbf{p}$ suggesting the KR rate is particularly slow for these substrates (entries 21, 23). However, 4o and $4 p$ were isolated with $99 \%$ and $96 \%$ ee respectively. Based on these results, the efficiency of this process depends both on the enantioselectivity of the vinylogous cycloaddition (first step), determining 
the chemical yield and on the KR (second step) establishing the enantioselectivity of the general process. This ATC process is efficient in $1 \mathrm{mmol} \mathrm{scale}$ to produce $\mathbf{4 a}$ as enantioenriched compound with $99 \%$ ee (scheme 4). Moreover, all the catalyst is easily recovered. ${ }^{[15]}$

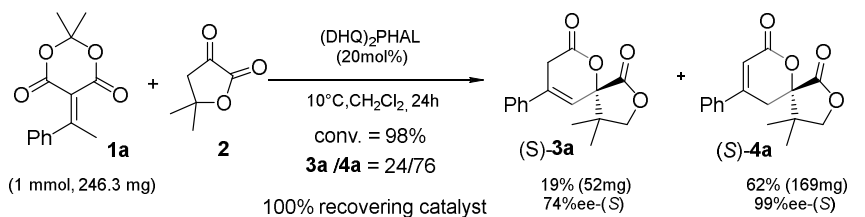

Scheme 4. Large scale Auto Tandem Catalysis with benzylidene 1a and dihydro-4,4-dimethyl-2,3-furandione 2.

The chemical process is summarized in scheme 5. It is related to the asymmetric formation of the spiro stereogenic center catalyzed by (DHQ $)_{2}$ PHAL leading to the non-conjugated lactone 3a as an enantioenriched mixture (cycle I). ${ }^{[8]}$ The second cycle consists in the isomerization of $(S)$-3a to conjugated lactone $(S)-\mathbf{4 a}$ via a kinetic resolution process controlled by the same catalyst (cycle II). This kinetic resolution operates through a 1,3-prototropic shift. Despite such transformation being well-documented in enantioselective catalysis, ${ }^{[16]}$ the present process ensures the amplification of enantiomeric excess. To the best of our knowledge, a kinetic resolution that proceeds through a 1,3-prototropic shift leading to an enantiomeric excess amplification has never been reported yet.

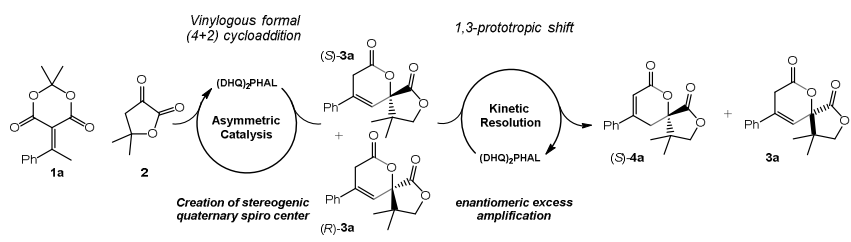

Scheme 5. Proposed enantioselective ATC process for the synthesis of spiro 5,6-dihydropyran-2-ones 4a-p.

The proposed catalytic sequence is shown in scheme 6 . The inside mechanism of the first cycle is based on our previous body of work. ${ }^{[8]}$ Based on a study by Dixon and co-workers, ${ }^{[16 \mathrm{~d}]}$ basic catalyst deprotonates the weakly acidic $\alpha$-position of $(S)$-3a to form the intermediate $(S)$-I. A regioselective reprotonation of the extended enolate $(S)$-I would then occur preferentially at the $\gamma$-position to afford the product $(S)-\mathbf{4 a}$.

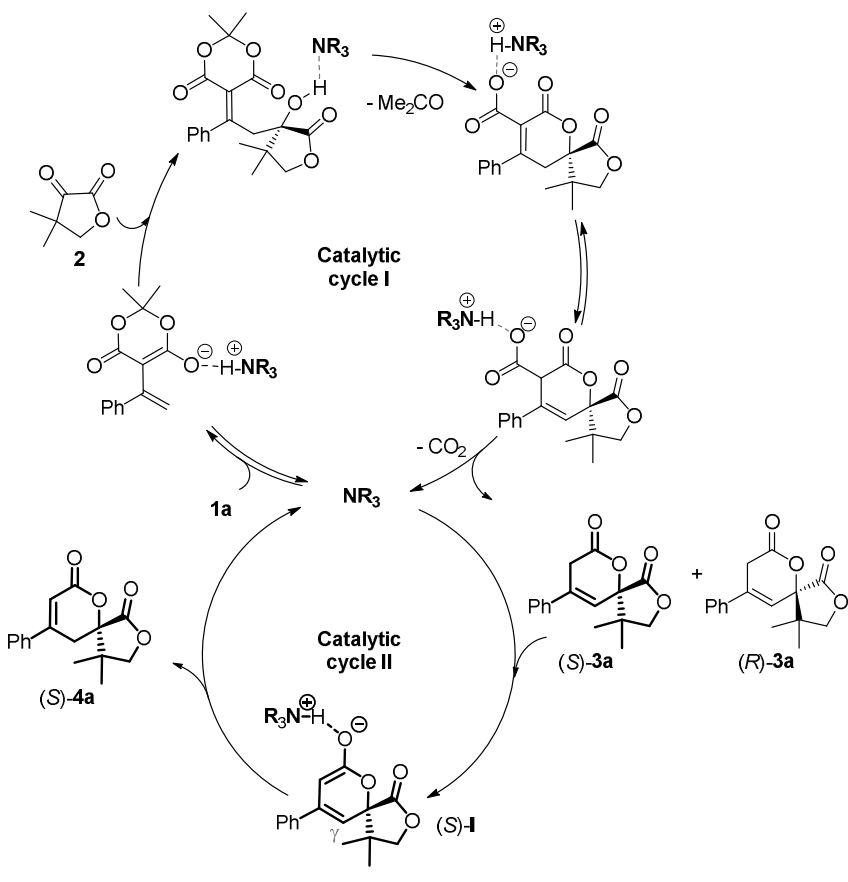

Scheme 6. Proposed mechanism for the synthesis of spiro 5,6-dihydropyran-2-ones $\mathbf{4 a - p}$ by ATC process.

In conclusion, we describe for the first time an Auto Tandem Catalysis (ATC) process including an enantioselective vinylogous formal $(4+2)$ cycloaddition followed by a kinetic resolution (KR) leading to enantioenriched-final product. This KR process proceeds through a 1,3-prototropic shift. The system leads to a high selectivity for the preparation of 5,6-dihydropyran-2-one as original spiro-[4,5]decanes 4a-p with a quaternary stereocenter. This ATC sequence capitalizes on the cooperative effect of $(\mathrm{DHQ})_{2}$ PHAL organocatalyst on the two enantiodeterminating steps allowing to overcome the maximum of $50 \%$ yield which could be usually reached in regular KR-processes.

\section{Experimental Section}

General procedure for Auto Tandem Catalysis of 5,6dihydropyran-2-ones 4a-p: Meldrum's acid derivative 1a-p $(0.15 \mathrm{mmol})$ and dihydro-4,4-dimethyl-2,3-furandione $\mathbf{2}$ $(0.15 \mathrm{mmol}, 19.5 \mathrm{mg})$ were diluted in dry $\mathrm{CH}_{2} \mathrm{Cl}_{2}(0.3 \mathrm{~mL}$, $0.5 \mathrm{M}$ ) and (DHQ) 2 PHAL (20 mol\%, $23.9 \mathrm{mg}$ ) was added. After stirring at the desired temperature for 24 hours under argon atmosphere, the reaction was filtered on a pad of silica gel [eluent: Petroleum Ether/EtOAc (6/4)] to remove catalyst and concentrated in vacuo at $30^{\circ} \mathrm{C}$ to avoid the possible non-catalyzed thermodynamic isomerization of 3a to $\mathbf{4 a}$. Conversion and 3a-p /4a-p ratio were determined by ${ }^{1} \mathrm{H}$ NMR on the crude product. The residue was purified by column chromatography on silica gel to separate the desired spirolactones 3a-p and $\mathbf{4 a - p}$. 23.9 $\mathrm{mg}$ of clean (DHQ) 2 PHAL were isolated by washing the pad of silica with eluent $\left[\mathrm{CH}_{2} \mathrm{Cl}_{2} / \mathrm{MeOH}(9 / 1)\right]$ and concentrated in vacuo (100\% recovered).

Detailed experimental procedures for substrates synthesis, kinetic resolution of racemic 3a, NMR-, HPLC-spectra and crystallographic data can be found in the supporting information. 


\section{Acknowledgements}

This work was supported by the Centre National de la Recherche Scientifique (C.N.R.S), funded by the french government. The author thanks Dr. Amélie Duraud for proof-reading.

\section{References}

[1]a) D. E. Fogg, E. N. dos Santos, Coord. Chem. Rev. 2004, 248, 2365-2379; b) N. T. Patil, V. S. Shinde, B. Gajula, Org. Biomol. Chem. 2012, 10, 211-224; c).S. M. Inamdar, V. S. Shinde, N. T. Patil, Org. Biomol. Chem. 2015, 13, 8116-8162; d) T. L. Lohr, T. J.Marks, Nat. Chem. 2015, 7, 477-482; e) J. Zhou, Multicatalyst System in Asymmetric Catalysis, Wiley, 2015; f) A. Galván, F. J. Fañanás, F. Rodríguez, Eur. J. Inorg. Chem. 2016, 1306-1313; g) G. Szőllősi, Catal. Sci.Technol. 2018, 8, 389-422; h) J. F. Campos, S. Berteina-Raboin, Catalysis, 2020, 10, 631; i) S. P. Sancheti, Urvashi, M. P. Shah, N. T. Patil, ACS Catal. 2020, 10, 3462-3489; j) R. Calmanti, M. Selva, A. Perosa, Green Chem, 2021, 23, 1921-1941; q) S. Martínez, L. Veth, B. Lainer, P. Dydio, ACS Catal. 2021, 11, 3891-3915.

[2] a) N. Shindoh, Y. Takemoto, K. Takasu, Chem. Eur. J. 2009, 15, 12168-12179; b) J.E. Camp, Eur. J. Org. Chem. 2017, 425-433; c) R. Barroso, M. P. Cabal, C. Valdés, Synthesis, 2017, 49, 4434-4447.

[3] In addition of ATC process, an interesting organocatalytic iterative sequence was developped by $\mathrm{T}$. Soós and coworkers. a) S. Varga, G. Jakab, L. Drahos, T. Holczbauer, M. Czugler, T. Soós, Org. Lett. 2011, 13, 5416-5419; b) S. Varga, G. Jakab, A. Csámpai, T. Soós, J. Org. Chem. 2015, 80, 8990-8996.

[4] Selected examples of Auto Tandem Catalysis: a) H. Ueda, M. Yamaguchi, H. Kameya, K. Sugimoto, H. Tokuyama, Org. Lett. 2014, 16, 4948-4951; c) S. Das, D. Hong, Z. Chen, Z. She, W. H. Hersh, G. Subramaniam, Y. Chen, Org. Lett. 2015, 17, 5578-5581; d) R. Mancuso, A. Maner, I. Ziccarelli, C. Pomelli, C. Chiappe, N. Della. Ca', L. Veltri, B. Gabriele, Molecules, 2016, 21, 897905; e) A. R. O. Venning, M. R. Kwiatkowski, J. E. Roque Peça, B. C. Lainhart, A. A. Guruparan, E. J. Alexanian, J. Am. Chem. Soc. 2017, 139, 11595-11600; f) M. Bakos, Á. Gyömöre, A. Domján, T. Soós, Angew. Chem. Int. Ed. 2017, 56, 5217-5221; Angew. Chem. 2017, 129, 5301-5305; g) R. Barroso, M. Paraja, M.-P. Cabal, C. Valdes, Org. Lett. 2017, 19, 4086-4089; h) W. Huang, C. Liu, Y. Gu, Adv. Synth. Catal. 2017, 359, 1811-1818; i) C. J. C. Lamb, B. G. Nderitu, G. McMurdo, J. M. Tobin, F. Vilela, A.-L. Lee, Chem. Eur. J. 2017, 23, 18282-18288; j) A. Kondoh, M. Terada, Org. Lett. 2018, 20, 5309-5313; k) W. Zhang, C. Meng, Y. Liu, Y. Tang, F. Li, Adv. Synth. Catal. 2018, 360, 3751-3759; 1) P. Chen, Z.-C. Chen, Y. Li, Q. Ouyang,W. Du, Y.-C. Chen, Angew. Chem. Int. Ed. 2019, 58, 4036-4040; Angew. Chem. 2019, 131, 4076-4080; m) B. C. Roy, Sk. A. Samim, D. Panja, S. Kundu, Catal. Sci.Technol. 2019, 9, 6002-6006; n) P. T. K. Arachchige, C. S. Yi, Org. Lett. 2019, 21, 3337-3341; o) A. Kondoh, C. Ma, M. Terada, Chem. Commun. 2020, 56, 10894-10897; p) J. R.
Alexander, V. I. Shchepetkina, K. S. Stankevich, R. J. Benedict, S. P. Bernhard, R. J. Dreiling, M. J. Cook, Org. Lett. 2021 23, 559-564.

[5] For enantioselective Auto Tandem Catalysis, see: a ) D. Enders, M. R. Hûttl, C. Grondal, G; Raabe, Nature, 2006, 441, 861-863; b) J. Barluenga, N. Quiñones, M.-P. Cabal, F. Aznar, C. Valdés, Angew. Chem. Int. Ed. 2011, 50, 2350-2353; Angew.Chem. 2011, 123, 2398-2401; c) N. Kanbayashi, K. Takenaka, T. Okamura, K. Onitsuka, Angew. Chem. Int. Ed. 2013, 52, 4897-4901; Angew. Chem. 2013, 125, 4997-5001; d) J. Long, R. Yu, J. Gao, X. Fang, Angew. Chem. Int. Ed. 2020, 59, 6785-6789; Angew. Chem. 2020, 132, 6851-6855; e) M. Wang, M. Zhou, L. Zhang, Z. Zhang, Wanbin Zhang, Chem. Sci., 2020, 11, 4801-4807.

[6] a) V. Boucard, G. Broustal, J-M. Campagne, Eur. J. Org. Chem, 2007, 225-236; b) J. Marco, M. Carda, J. Murga, E. Falomir, Tetrahedron, 2007, 63, 2929-2958; c) K. Eskandari, M. Rafieian-Kopaei, Chem. Heterocycl. Comp. 2016, 158-160; d) A. Axelsson, E. Hammarvid, M. Rahm, H. Sundén, Eur. J. Org. Chem, 2020, 54365444.

[7] a) Z-G. Zhang, J-H. Fu, F. Sha, X-Y. Wu, Tetrahedron, 2018, 74, 3557-3563; b) H. Joshi, A. Yadav, A. Das, V. K. Singh, J. Org. Chem. 2020, 85, 3202-3212; c) C. Curti, L. Battistini, A. Sartori, F. Zanardi, Chem. Rev. 2020, 120, 2448-2612.

[8] S. Wittmann, T. Martzel, C. T. Pham Truong, M. Toffano, S. Oudeyer, R. Guillot, C. Bournaud, V. Gandon, J.-F. Brière, G. Vo-Thanh. Angew. Chem. Int. Ed. 2021, 60, 11110-11114; Angew. Chem. 2021, 133, 11210-11214.

[9] For reviews on catalytic transformations of Meldrum's acid derivatives, see: a) A. M. Dumas, E. Fillion, Acc. Chem. Res. 2010, 43, 440; b) E. Pair, T. Cadart, V. Levacher, J.-F. Brière, ChemCatChem. 2016, 8, 18821890.

[10] a) P. S. Tiseni, R. Peters, Angew. Chem. Int. Ed. 2007, 46, 5325-5328; Angew. Chem. 2007, 119, 5419-5422; b) P. S. Tiseni, R. Peters, Chem. Eur. J. 2010, 16, 25032517.

[11] See SI for conversion, $\mathbf{3 a} / \mathbf{4 a}$ ratio and enantiomeric excesses value.

[12] $\mathrm{E}$ value is calculated from $\mathrm{E}=[\log ((1-\mathrm{c})(1-$ ee $3 a)] /\left[\log \left((1-c)\left(1+e_{3 a}\right)\right]\right.$ and $c=e_{3 a} /\left(e_{3 a}+e_{4 a}\right)$. See H. B. Kagan, J. C. Fiaud, Topics in Stereochemistry, (Eds.: E. L. Eliel et S. Wilen), John Wiley \& Sons. 1988, 18, 249-330.

[13] The optimal temperature at $10^{\circ} \mathrm{C}$ was determinated to offer the best enantioselectivity (Table1). The preparation of new racemic compounds 3a-p or $\mathbf{4 a - p}$ were obtained from basic catalysis to give pure samples (see SI).

[14] Based on the $(S)$-absolute configuration and the levorotation for compounds $4 \mathbf{a}, \mathbf{4 b}, \mathbf{4 c}, \mathbf{4 d}, \mathbf{4 g}, \mathbf{4 i}, \mathbf{4 j}, \mathbf{4 k}$ and $\mathbf{4 n}$, we suppose a same $(S)$-configuration for $\mathbf{4 e}, \mathbf{4 f}$ 4h, 4l, 4m, 40 and $4 p$ which are levorotary compounds. 
CCDC 1992495, 2062725 \& 2045183-2045189 contains the supplementary crystallographic data for this paper. These data can be obtained free of charge from the Cambridge Crystallographic Data Centre via http://www.ccdc.cam.ac.uk/Community/.

[15] $100 \%$ of the catalyst was recovered after reaction (see experimental section)

[16] a) Y. Wu, R. P. Singh, L. Deng, J. Am. Chem. Soc. 2011, 133, 12458-12461; b) J. H. Lee, L. Deng, J. Am. Chem.
Soc. 2012, 134, 18209-18212; c) X-S. Xue, X. Li, A. Yu, C. Yang, C. Song, J.-P. Cheng, J. Am. Chem. Soc. 2013, 135, 7462-7473; d) J. C. Golec, E. M. Carter; J. W. Werd, W. G. Whittingham, L. Simón R. S. Paton, D. J. Dixon, Angew. Chem. Int. Ed. 2020, 59, 17417-17422; Angew. Chem. 2020, 132, 17570-17575. 
Auto Tandem Catalysis: Asymmetric Vinylogous Cycloaddition/Kinetic Resolution Sequence for the Enantioselective Synthesis of Spiro-

Dihydropyranone from Benzylidene Meldrum's Acid.

Adv. Synth. Catal. Year, Volume, Page - Page

Martial Toffano*, Régis Guillot, Chloée Bournaud, Jean-François Brière and Giang Vo-Thanh
Enantioselective Auto Tandem Catalysis

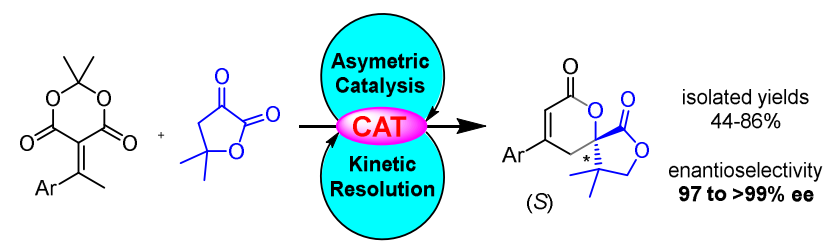

